TAHERI A. ${ }^{1}$, FARAJZADEH A.P. ${ }^{2}$

\title{
A NEW GENERALIZATION OF $\alpha$-TYPE ALMOST- $F$-CONTRACTIONS AND $\alpha$-TYPE F-SUZUKI CONTRACTIONS IN METRIC SPACES AND THEIR FIXED POINT THEOREMS
}

\begin{abstract}
In this paper a new generalization of $\alpha$-type almost- $F$-contractions and an extension of $\alpha$-type $F$-Suzuki contractions are given. Moreover, some new fixed point theorems of them are discussed. Some examples and applications in order to illustrate the main results are presented. The results of this article can be considered as improvements of some well-known results appeared in the literature.

Key words and phrases: $\alpha$-type almost- $F$-contraction, $\alpha$-type $F$-Suzuki contraction.
\end{abstract}

\footnotetext{
${ }^{1}$ Department of Mathematics, Science and Research Branch, Islamic Azad University, 14515-775, Tehran, Iran

2 Department of Mathematics, Razi University, 67149, Kermanshah, Iran

E-mail: aghiltaheri@yahoo.com(Taheri A.), farajzadehali@gmail.com (Farajzadeh A.P.)
}

\section{INTRODUCTION}

After innovation of the Banach contraction principle [2], fixed point theory, which was one of the most celebrated tool in nonlinear analysis, acquires a distinguished role in research activity. Due to its applications in the nonlinear integro-differential equations, nonlinear Volterra integral equations, game theory etc, existence of a fixed point for contraction type mappings in metric spaces have been considered by many authors. see, for instance, $[4,12,13,17,19,22,23]$ and the references therein.

During the past decades, scholars extend this principle towards different contractions. Specially, in 2012, Wardowski [24] generalized it interestingly by introducing a new type of contractions called F-contractions. After presentation of F-contractions, many authors extended them in various forms. Some extensions and generalizations are obtained in $[1,6-11,14-21,25]$. Wardowski and Van Dung [25] (also independently Minak et al. [14]) with using Ćirić-type generalized contraction [5] in definition of $F$-contractions, introduced the notion of $F$-weak contractions and utilize the same to generalize the main result of [24].

Very recently (in 2016) Gopal et al. [7] generalized it by introducing the concept of $\alpha$-type F-contraction. On the other hand, In 2014 Piri and Kumam [16] extended the results of Wardowski [24] by introducing the concept of an F-Suzuki contraction. Also, in the same year, Minak et al. [14] introduced a new concept of an almost- $F$-contraction. Most recently (in 2016) Budhia et al. [3] introduced the new concepts of an $\alpha$-type almost- $F$-contraction and an $\alpha$-type $F$-Suzuki contraction and proved some fixed point theorems concerning such contractions. In this research, we extended the results of [7] and [3], by introducing a new type of contractions that is called $\alpha$-type almost- $F$-weak contraction and an $\alpha$-type $F$-weak Suzuki contraction.

$\mathrm{y} \Delta \mathrm{K} 517.988 .523$

2010 Mathematics Subject Classification: 47H10, 54H25, 37C25.

(C) Taheri A., Farajzadeh A.P., 2019 


\section{PRELIMINARIES}

Here, we express a series of definitions of some fundamental notions.

First, let us, following [24], denote with $\mathcal{F}$ the family of all functions $F:(0,+\infty) \rightarrow \mathbb{R}$ that satisfy the following conditions:

(F1) F is strictly increasing,

(F2) for every sequence $\left\{\alpha_{n}\right\}$ in $(0,+\infty)$, we have $\lim _{n \rightarrow \infty} F\left(\alpha_{n}\right)=-\infty$ iff $\lim _{n \rightarrow \infty} \alpha_{n}=0$,

(F3) there exists a number $k \in(0,1)$ such that $\lim _{\alpha \rightarrow 0^{+}} \alpha^{k} F(\alpha)=-\infty$.

And following [20], denote by $\mathcal{G}$ the collection of all functions $F:(0,+\infty) \rightarrow \mathbb{R}$ satisfying the following conditions:

(G1) $F$ is strictly increasing,

(G2) there exists a sequence $\left\{\alpha_{n}\right\}$ in $(0,+\infty)$ such that $\lim _{n \rightarrow \infty} F\left(\alpha_{n}\right)=-\infty$, or $\inf F=-\infty$,

(G3) $F$ is a continuous map.

Example 1 ([3]). The following functions belong to $\mathcal{F}$ :

$$
F(\alpha)=\ln \alpha, F(\alpha)=\ln \alpha+\alpha, \quad F(\alpha)=-\frac{1}{\sqrt{\alpha}},
$$

and the following functions $F:(0,+\infty) \rightarrow \mathbb{R}$ belongs to $\mathcal{G}$ :

$$
F(\alpha)=\ln \alpha, F(\alpha)=-\frac{1}{\alpha}+\alpha, F(\alpha)=-\frac{1}{\alpha} .
$$

Definition 1 ([24]). Let $(X, d)$ be a metric space. The mapping $T: X \rightarrow X$ is called an $F$-contraction, if there exist $F \in \mathcal{F}$ and $\tau>0$ such that, for all $x, y \in X$ with $d(T x, T y)>0$, we have

$$
\tau+F(d(T x, T y)) \leq F(d(x, y)) .
$$

Example 2 ([24], Example 2.1). It is easy to verify that every Banach contraction is an $F$-contraction with $F(t)=\ln t$ and $\tau=\ln r$. For more details and examples see [24].

Definition 2 ([25]). Let $(X, d)$ be a metric space. The mapping $T: X \rightarrow X$ is called an $F$-weak contraction on $X$ if there exist $F \in \mathcal{F}$ and $\tau>0$ such that, for all $x, y \in X$ with $d(T x, T y)>0$, we have

$$
\tau+F(d(T x, T y)) \leq F(m(x, y))
$$

where

$$
m(x, y)=\max \left\{d(x, y), d(x, T x), d(y, T y), \frac{d(x, T y)+d(y, T x)}{2}\right\} .
$$

Remark 1. Every F-contraction is an F-weak contraction but converse is not necessarily true [25].

Definition 3 ([25]). Let $(X, d)$ be a metric space and $\alpha: X \times X \rightarrow(0,+\infty) \cup\{-\infty\}$ be a symmetric function. The mapping $T: X \rightarrow X$ is called an $\alpha$-type $F$-contraction on $X$ if there exist $F \in \mathcal{F}$ and $\tau>0$ such that, for all $x, y \in X$ with $d(T x, T y)>0$, we have

$$
\tau+\alpha(x, y) F(d(T x, T y)) \leq F(d(x, y)) .
$$


Definition 4 ([25]). Let $(X, d)$ be a metric space and $\alpha: X \times X \rightarrow(0,+\infty) \cup\{-\infty\}$ be a symmetric function. The mapping $T: X \rightarrow X$ is called an $\alpha$-type $F$-weak contraction on $X$ if there exist $F \in \mathcal{F}$ and $\tau>0$ such that, for all $x, y \in X$ with $d(T x, T y)>0$, we have

$$
\tau+\alpha(x, y) F(d(T x, T y)) \leq F(m(x, y)),
$$

where

$$
m(x, y)=\max \left\{d(x, y), d(x, T x), d(y, T y), \frac{d(x, T y)+d(y, T x)}{2}\right\} .
$$

Remark 2. Every $\alpha$-type F-contraction is an $\alpha$-type F-weak contraction but the converse is not necessarily true.

Remark 3. It is clear that every $F$-weak contraction is an $\alpha$-type F-weak contraction with $\alpha(x, y)=1$, for all $x, y \in X$. But every $\alpha$-type $F$-weak contraction is not necessarily an $F$-weak contraction. For example, see ([25], Example 3.4).

Definition 5 ([14]). Let $(X, d)$ be a metric space. The mapping $T: X \rightarrow X$ is said to be an almost-F-contraction, if there exist $F \in \mathcal{F}, \tau>0$ and $L \geq 0$ such that for all $x, y \in X$,

$$
d(T x, T y)>0 \Rightarrow \tau+F(d(T x, T y)) \leq F(d(x, y)+L d(y, T x))
$$

and

$$
d(T x, T y)>0 \Rightarrow \tau+F(d(T x, T y)) \leq F(d(x, y)+L d(x, T y)) .
$$

Remark 4. Every F-contraction is an almost-F-contraction with $L=0$, but the converse is not necessarily true [14]. Also, it is obvious that every F-weak contraction is an $\alpha$-type F-weak contraction with $\alpha(x, y)=1$, for all $x, y \in X$, but the converse is not necessarily true. For examples, see [14].

Definition 6 ([3]). Let $(X, d)$ be a metric space. The mapping $T: X \rightarrow X$ is said to be an $\alpha$-type almost- $F$-contraction, if there exist $F \in \mathcal{F}$ and $\tau>0$ and $L \geq 0$ such that for all $x, y \in X$,

$$
d(T x, T y)>0 \Rightarrow \tau+F(d(T x, T y)) \leq F(d(x, y)+L d(y, T x))
$$

and

$$
d(T x, T y)>0 \Rightarrow \tau+F(d(T x, T y)) \leq F(d(x, y)+L d(x, T y)) .
$$

Remark 5. Every almost-F-contraction is an $\alpha$-type almost-F-contraction with $\alpha(x, y)=1$, for all $x, y \in X$. But the converse is not necessarily true. For some examples, see [3, Example 3.1].

Definition 7 ([16]). Let $(X, d)$ be a metric space. A mapping $T: X \rightarrow X$ is said to be an $F$-Suzuki contraction if there exist $F \in \mathcal{G}$ and $\tau>0$ such that for all $x, y \in X$ with $T x \neq T y$

$$
\frac{1}{2} d(x, T x) \leq d(x, y) \quad \text { implies that } \tau+F(d(T x, T y)) \leq F(d(x, y)) .
$$

Definition 8 ([3]). Let $(X, d)$ be a metric space and $\alpha: X \times X \rightarrow(0,+\infty) \cup\{-\infty\}$ be a symmetric function. The mapping $T: X \rightarrow X$ is said to be an $\alpha$-type F-Suzuki contraction if there exist $F \in \mathcal{G}$ and $\tau>0$ such that for all $x, y \in X$ with $T x \neq T y$

$$
\frac{1}{2} d(x, T x) \leq d(x, y) \quad \text { implies that } \tau+\alpha(x, y) F(d(T x, T y)) \leq F(d(x, y)) .
$$


Remark 6. Every $\alpha$-type F-Suzuki contraction is an F-Suzuki contraction with $\alpha(x, y)=1$, for all $x, y \in X$. But the converse is not necessarily true. For example, see [3, Example 3.2].

Definition 9 ([19]). Let $\alpha: X \times X \rightarrow(0,+\infty)$ be a given mapping. The mapping $T: X \rightarrow X$ is said to be an $\alpha$-admissible, whenever $\alpha(T x, T y) \geq 1$ provided $\alpha(x, y) \geq 1$ and $x, y \in X$.

Definition 10. An $\alpha$-admissible map $T$ is said to have the K-property, if for each sequence $\left\{x_{n}\right\} \subseteq X$ with $\alpha\left(x_{n}, x_{n+1}\right) \geq 1$, for all $n \in \mathbb{N}$, there exists a natural number $k$ such that $\alpha\left(T x_{n}, T x_{m}\right) \geq 1$, for all $m>n \geq k$.

We state the following lemmas which are useful in proving our main results.

Lemma 1 ([16]). Let $F:(0,+\infty) \rightarrow \mathbb{R}$ be an increasing function and $\left\{\alpha_{n}\right\}$ be a sequence of positive real numbers. Then, the following holds:

(a) if $\lim _{n \rightarrow \infty} F\left(\alpha_{n}\right)=-\infty$, then $\lim _{n \rightarrow \infty} \alpha_{n}=0$,

(b) if $\inf F=-\infty$ and $\lim _{n \rightarrow \infty} \alpha_{n}=0$, then $\lim _{n \rightarrow \infty} F\left(\alpha_{n}\right)=-\infty$.

Lemma 2 ([4]). Let $(X, d)$ be a metric space, and $\left\{x_{n}\right\}$ be a sequence in $X$ such that $\lim _{n \rightarrow \infty} d\left(x_{n}, x_{n+1}\right)=0$. If $\left\{x_{n}\right\}$ is not a Cauchy sequence then there exists $\varepsilon>0$ and two sequences of positive integers $\left\{n_{k}\right\}$ and $\left\{m_{k}\right\}$ with $n_{k}>m_{k}>k$ such that $d\left(x_{m_{k}}, x_{n_{k}}\right)>\varepsilon$, $d\left(x_{m_{k}}, x_{n_{k}-1}\right)<\varepsilon$ and

(1) $\lim _{k \rightarrow \infty} d\left(x_{m_{k}}, x_{n_{k}}\right)=\varepsilon$,

(2) $\lim _{k \rightarrow \infty} d\left(x_{m_{k}-1}, x_{n_{k}}\right)=\varepsilon$,

(3) $\lim _{k \rightarrow \infty} d\left(x_{m_{k}}, x_{n_{k}+1}\right)=\varepsilon$,

(4) $\lim _{k \rightarrow \infty} d\left(x_{m_{k}-1}, x_{n_{k}+1}\right)=\varepsilon$.

\section{MAIN RESUlTS}

In this section, two new contractions are introduced. In the first part of this section, the concept of an $\alpha$-type almost- $F$-weak contraction is defined in metric spaces. And in the second part the concept of an $\alpha$-type $F$-weak Suzuki contraction is introduced. Some fixed point theorems for these contractions are proved and suitable examples are furnished to demonstrate the validity of the hypotheses of our results and reality of our generalizations.

We commence our main result with the following definition.

Definition 11. Let $(X, d)$ be a metric space and $\alpha: X \times X \rightarrow(0,+\infty) \cup\{-\infty\}$ be a symmetric function. The mapping $T: X \rightarrow X$ is said to be an $\alpha$-type almost- $F$-weak contraction (for simplicity we write almost- $\alpha$ F-weak contraction), if there exist $F \in \mathcal{F}, \tau>0$ and $L \geq 0$ such that $d(T x, T y)>0$ implies that

$$
\tau+\alpha(x, y) F(d(T x, T y)) \leq F\left(m(x, y)+L N_{1}(x, y)\right)
$$

where

$$
m(x, y)=\max \left\{d(x, y), d(x, T x), d(y, T y), \frac{d(x, T y)+d(y, T x)}{2}\right\},
$$

and

$$
N_{1}(x, y)=\min \{d(x, T y), d(y, T x)\}
$$


Example 3. Let $X=\{(0,0),(0,4),(5,0),(4,5)\}$ be endowed with the metric defined by

$$
d\left(\left(x_{1}, x_{2}\right),\left(y_{1}, y_{2}\right)\right)=\left|x_{1}-y_{1}\right|+\left|x_{2}-y_{2}\right| \text {. }
$$

It is easy to see that $(X, d)$ is a complete metric space.

Suppose that $T: X \rightarrow X$ is defined as follows :

$$
T(0,0)=T(5,0)=T(0,4)=(0,0), T(4,5)=(5,0) .
$$

Furthermore, suppose $\alpha\left(\left(x_{1}, x_{2}\right),\left(y_{1}, y_{2}\right)\right)=1$, for all $\left(x_{1}, x_{2}\right),\left(y_{1}, y_{2}\right) \in X$. It is easily verified that, for each $F \in \mathcal{F}$, the mapping $T$ is not an $\alpha$-type almost- $F$-contraction. Indeed, for any $\tau>0$ and $F \in \mathcal{F}$, we have

$$
\tau+\alpha((0,4),(4,5)) F(d(T(0,4), T(4,5)))=\tau+F(d((0,0),(5,0)))=\tau+F(5) .
$$

On the other hand, we have

$$
F(d((0,4),(4,5))+L d((4,5), T(0,4)))=F(5) .
$$

And $\tau+F(5)>F(5)$. So, $T$ is not an $\alpha$-type almost-F-contraction. But, one can easily see that, for $0<\tau<\ln \frac{6}{5}$ and $F(t)=\ln t$, if $d\left(T\left(x_{1}, x_{2}\right), T\left(y_{1}, y_{2}\right)\right)>0$ then

$$
\begin{aligned}
& \tau+\alpha\left(\left(x_{1}, x_{2}\right),\left(y_{1}, y_{2}\right)\right) F\left(d\left(T\left(x_{1}, x_{2}\right), T\left(y_{1}, y_{2}\right)\right)\right) \leq F\left(m\left(\left(x_{1}, x_{2}\right),\left(y_{1}, y_{2}\right)\right)+\right. \\
& \left.\operatorname{LN}_{1}\left(\left(x_{1}, x_{2}\right),\left(y_{1}, y_{2}\right)\right)\right)
\end{aligned}
$$

where

$$
\begin{aligned}
m\left(\left(x_{1}, x_{2}\right),\left(y_{1}, y_{2}\right)\right)= & \max \left\{d\left(\left(x_{1}, x_{2}\right),\left(y_{1}, y_{2}\right)\right), d\left(\left(x_{1}, x_{2}\right), T\left(x_{1}, x_{2}\right)\right),\right. \\
& \left.d\left(\left(y_{1}, y_{2}\right), T\left(y_{1}, y_{2}\right)\right), \frac{d\left(\left(x_{1}, x_{2}\right), T\left(y_{1}, y_{2}\right)\right)+d\left(\left(y_{1}, y_{2}\right), T\left(x_{1}, x_{2}\right)\right)}{2}\right\},
\end{aligned}
$$

and

$$
N_{1}\left(\left(x_{1}, x_{2}\right),\left(y_{1}, y_{2}\right)\right)=\min \left\{d\left(\left(x_{1}, x_{2}\right), T\left(y_{1}, y_{2}\right)\right), d\left(\left(y_{1}, y_{2}\right), T\left(x_{1}, x_{2}\right)\right)\right\}
$$

For example $d(T(0,4), T(4,5))=d((0,0),(5,0))=5>0$ and

$$
\begin{aligned}
m((0,4),(4,5))= & \max \{d((0,4),(4,5)), d((0,4), T(0,4)), d((4,5), T(4,5)), \\
& \left.\frac{d((0,4), T(4,5))+d((4,5), T(0,4))}{2}\right\}=\max \left\{5,4,6, \frac{9+9}{2}\right\}=9,
\end{aligned}
$$


and we have

$$
\tau+\alpha((0,4),(4,5)) F(d(T(0,4), T(4,5)))=\tau+F(5)<\ln \frac{6}{5}+\ln 5=\ln 6 .
$$

On the other hand, we have

$$
F\left(m((0,4),(4,5))+L N_{1}((0,4),(4,5))\right)=F(9)=\ln 9 .
$$

Hence,

$$
\tau+\alpha((0,4),(4,5)) F(d(T(0,4), T(4,5)))<F\left(m((0,4),(4,5))+L N_{1}((0,4),(4,5))\right) .
$$

Or for $(5,0)$ and $(4,5)$, we have $d(T(5,0), T(4,5))=d((0,0),(5,0))=5>0$ and

$$
\begin{aligned}
m((5,0),(4,5))= & \max \{d((5,0),(4,5)), d((5,0), T(5,0)), d((4,5), T(4,5)), \\
& \left.\frac{d((5,0), T(4,5))+d((4,5), T(5,0))}{2}\right\}=\max \left\{6,5,6, \frac{0+9}{2}\right\}=6,
\end{aligned}
$$

and we have

$$
\tau+\alpha((5,0),(4,5)) F(d(T(5,0), T(4,5)))=\tau+F(5)<\ln \frac{6}{5}+\ln 5=\ln 6 .
$$

On the other hand, we have

$$
F\left(m((5,0),(4,5))+L N_{1}((5,0),(4,5))\right)=F(6)=\ln 6
$$

Hence,

$$
\tau+\alpha((5,0),(4,5)) F(d(T(5,0), T(4,5))) \leq F\left(m((5,0),(4,5))+L N_{1}((5,0),(4,5))\right) .
$$

In the same manner, we can easily check that (1) is satisfied for $(0,0)$ and $(4,5)$. Therefore, $T$ is an almost- $\alpha$ F-weak contraction.

Now, we present our first result.

Theorem 1. Let $(X, d)$ be a complete metric space, $\alpha: X \times X \rightarrow(0,+\infty) \cup\{-\infty\}$ be a symmetric function, $F \in \mathcal{F}$ and $T: X \rightarrow X$ be an almost- $\alpha$ F-weak contraction satisfying the following conditions:

(i) $T$ is $\alpha$-admissible,

(ii) there exists $x_{0} \in X$ such that $\alpha\left(x_{0}, T x_{0}\right) \geq 1$,

(iii) if $\left\{x_{n}\right\}$ is a sequence in $X$ such that $x_{n} \rightarrow x$ as $n \rightarrow \infty$ and $\alpha\left(x_{n}, x_{n+1}\right) \geq 1$, for all $n \in \mathbb{N}$, then $\alpha\left(x_{n}, x\right) \geq 1$, for all $n \in \mathbb{N}$. 
Then, if $T$ or $F$ is continuous then $T$ has a fixed point.

Proof. Let $x_{0} \in X$ be such that $\alpha\left(x_{0}, T x_{0}\right) \geq 1$. For any $n \in \mathbb{N}$, define:

$$
x_{n+1}=T\left(x_{n}\right) \text {. }
$$

If $x_{n_{0}+1}=x_{n_{0}}$ for some $n_{0} \in \mathbb{N}$ then $x_{n_{0}}$ is a fixed point of $T$. So, we can assume that $x_{n+1} \neq x_{n}$, for each $n \in \mathbb{N}$. Since $T$ is $\alpha$-admissible, one can easily obtain that

$$
\alpha\left(x_{n}, x_{n+1}\right) \geq 1, \forall n \in \mathbb{N}
$$

Now since $T$ is an almost- $\alpha F-$ weak contraction, there exist $\tau>0$ and $L \geq 0$ such that if $d(T x, T y)>0$, then

$$
\tau+\alpha(x, y) F(d(T x, T y)) \leq F\left(m(x, y)+L N_{1}(x, y)\right) .
$$

Therefore, by (2) and (3)

$$
\begin{aligned}
\tau+F\left(d\left(T x_{n}, T x_{n+1}\right)\right) & \leq \tau+\alpha\left(x_{n}, x_{n+1}\right) F\left(d\left(T x_{n}, T x_{n+1}\right)\right) \\
& \leq F\left(m\left(x_{n}, x_{n+1}\right)+L N_{1}\left(x_{n}, x_{n+1}\right)\right) \leq F\left(m\left(x_{n}, x_{n+1}\right)+L d\left(x_{n+1}, T x_{n}\right)\right) \\
& =F\left(m\left(x_{n}, x_{n+1}\right)+0\right)=F\left(m\left(x_{n}, x_{n+1}\right)\right) .
\end{aligned}
$$

Hence, we have

$$
\tau+F\left(d\left(x_{n+1}, x_{n+2}\right)\right) \leq F\left(m\left(x_{n}, x_{n+1}\right)\right)
$$

But

$$
\begin{aligned}
m\left(x_{n}, x_{n+1}\right) & =\max \left\{d\left(x_{n}, x_{n+1}\right), d\left(x_{n}, T x_{n}\right), d\left(x_{n+1}, T x_{n+1}\right), \frac{d\left(x_{n}, T x_{n+1}\right)+d\left(x_{n+1}, T x_{n}\right)}{2}\right\} \\
& =\max \left\{d\left(x_{n}, x_{n+1}\right), d\left(x_{n+1}, x_{n+2}\right), \frac{d\left(x_{n}, x_{n+2}\right)}{2}\right\} \\
& \leq \max \left\{d\left(x_{n}, x_{n+1}\right), d\left(x_{n+1}, x_{n+2}\right), \frac{d\left(x_{n}, x_{n+1}\right)+d\left(x_{n+1}, x_{n+2}\right)}{2}\right\} \\
& \leq \max \left\{d\left(x_{n}, x_{n+1}\right), d\left(x_{n+1}, x_{n+2}\right)\right\} .
\end{aligned}
$$

Now, if $d\left(x_{n_{0}+1}, x_{n_{0}+2}\right) \geq d\left(x_{n_{0}}, x_{n_{0}+1}\right)$ for some $n_{0} \in \mathbb{N}$, then

$$
m\left(x_{n_{0}}, x_{n_{0}+1}\right) \leq d\left(x_{n_{0}+1}, x_{n_{0}+2}\right),
$$

and since $F$ is strictly increasing,

$$
F\left(m\left(x_{n_{0}}, x_{n_{0}+1}\right)\right) \leq F\left(d\left(x_{n_{0}+1}, x_{n_{0}+2}\right)\right),
$$

so, it follow from (4)

$$
\tau+F\left(d\left(x_{n_{0}+1}, x_{n_{0}+2}\right)\right) \leq F\left(d\left(x_{n_{0}+1}, x_{n_{0}+2}\right)\right) .
$$

So, $\tau \leq 0$ is a contradiction. Consequently,

$$
d\left(x_{n+1}, x_{n+2}\right)<d\left(x_{n}, x_{n+1}\right), \forall n \in \mathbb{N} .
$$


Hence, from (4) and (5), we have

$$
\tau+F\left(d\left(x_{n+1}, x_{n+2}\right)\right) \leq F\left(d\left(x_{n}, x_{n+1}\right)\right),
$$

or

$$
F\left(d\left(x_{n+1}, x_{n+2}\right)\right) \leq F\left(d\left(x_{n}, x_{n+1}\right)\right)-\tau \text {. }
$$

In general, one can get

$$
F\left(d\left(x_{n+1}, x_{n+2}\right)\right) \leq F\left(d\left(x_{0}, x_{1}\right)\right)-n \tau .
$$

Hence $\lim _{n \rightarrow \infty} F\left(d\left(x_{n}, x_{n+1}\right)\right)=-\infty$. So, from $\left(F_{2}\right)$ we have,

$$
\lim _{n \rightarrow \infty} d\left(x_{n}, x_{n+1}\right)=0 \text {. }
$$

Therefore, with notice to $\left(F_{3}\right)$, there exists $k \in(0,1)$ such that

$$
\lim _{n \rightarrow \infty}\left(d\left(x_{n}, x_{n+1}\right)\right)^{k} F\left(d\left(x_{n}, x_{n+1}\right)\right)=0 .
$$

Now, (6) implies that

$$
\left(d\left(x_{n}, x_{n+1}\right)\right)^{k} F\left(d\left(x_{n}, x_{n+1}\right)\right) \leq\left(d\left(x_{n}, x_{n+1}\right)\right)^{k}\left(F\left(d\left(x_{0}, x_{1}\right)\right)-n \tau\right) .
$$

Then, it can be easily seen that

$$
\lim _{n \rightarrow \infty} n\left(d\left(x_{n}, x_{n+1}\right)\right)^{k}=0 .
$$

So, there exists $n_{0} \in \mathbb{N}$ such that

$$
d\left(x_{n}, x_{n+1}\right) \leq \frac{1}{n^{\frac{1}{k}}}, \quad \forall n \geq n_{0} .
$$

Consequently, if $m>n>n_{0}$, then

$$
d\left(x_{n}, x_{m}\right) \leq \sum_{i=n}^{m} d\left(x_{i}, x_{i+1}\right) \leq \sum_{i=n}^{m} \frac{1}{i \frac{1}{k}} \leq \sum_{i=n_{0}}^{\infty} \frac{1}{i \frac{1}{k}} .
$$

Since $k \in(0,1)$, the series $\sum_{i=n_{0}}^{\infty} \frac{1}{i \frac{1}{k}}$ is convergent. Therefore, $\left\{x_{n}\right\}$ is a Cauchy sequence, and since $X$ is complete, there exists $u \in X$ such that $x_{n} \rightarrow u$ as $n \rightarrow \infty$. We claim that $u$ is a fixed point of $T$.

To prove the claim, at first suppose that $T$ is continuous, then we have

$$
u=\lim _{n \rightarrow \infty} x_{n+1}=\lim _{n \rightarrow \infty} T x_{n}=T(u),
$$

and so $u$ is a fixed point of $T$. Now, suppose that $F$ is continuous and in contrary, suppose that $T u \neq u$. Without lose of generality, one can assume that there exists $n_{0} \in \mathbb{N}$ such that $T x_{n} \neq T u$, for all $n \geq n_{0}$. (Indeed, if $x_{n+1}=T x_{n}=T u$ for infinite values of $n$, then uniqueness of the limit concludes that $T u=u$ ).

From (iii) and (4), we have

$$
\begin{aligned}
\tau+F\left(d\left(T x_{n}, T u\right)\right) & \leq \tau+\alpha\left(x_{n}, u\right) F\left(d\left(T x_{n}, T u\right)\right) \leq F\left(m\left(x_{n}, u\right)+L N_{1}\left(x_{n}, u\right)\right) \\
& \leq F\left(m\left(x_{n}, u\right)+L d\left(T x_{n}, u\right)\right)=F\left(m\left(x_{n}, u\right)+L d\left(x_{n+1}, u\right)\right)
\end{aligned}
$$


And since $F$ is continuous, as $n \rightarrow \infty$ we get

$$
\tau+F(d(u, T u)) \leq F\left(\lim _{n \rightarrow \infty}\left(m\left(x_{n}, u\right)+L d\left(x_{n+1}, u\right)\right)\right),
$$

where

$$
m\left(x_{n}, u\right)=\max \left\{d\left(x_{n}, u\right), d\left(x_{n}, x_{n+1}\right), d(u, T u), \frac{d\left(x_{n}, T u\right)+d\left(u, x_{n+1}\right)}{2}\right\},
$$

so,

$$
\lim _{n \rightarrow \infty} m\left(x_{n}, u\right)=\max \left\{0,0, d(u, T u), \frac{d(u, T u)+0}{2}\right\}=d(u, T u) .
$$

Also, we have

$$
\lim _{n \rightarrow \infty} L d\left(x_{n+1}, u\right)=0
$$

Therefore, from (7) we have

$$
\tau+F(d(u, T u)) \leq F(d(u, T u)),
$$

which is contradicted by positivity of $\tau$. So, $d(u, T u)=0$ i.e. $T u=u$.

The next result establishes a sufficient condition for uniqueness of fixed point.

Theorem 2. Let $(X, d)$ be a complete metric space and $T: X \rightarrow X$ be a mapping for which there exist $F \in \mathcal{F}$ and $\tau>0$ and $L \geq 0$ such that $d(T x, T y)>0$ implies that

$$
\tau+\alpha(x, y) F(d(T x, T y)) \leq F\left(m(x, y)+L N_{2}(x, y)\right)
$$

where $m(x, y)$ is defined as in Definition 11 and

$$
N_{2}(x, y)=\min \{d(x, T x), d(x, T y), d(y, T x)\} .
$$

We further assume that $\alpha(x, y) \geq 1$, for each $x, y \in$ Fix $(T)$. Then if $T$ is satisfies the conditions (i), (ii) and (iii) of Theorem 1 and $T$ or $F$ is continuous, then $T$ has a unique fixed point.

Proof. It is clear that $T$ is an almost- $\alpha$ F-weak contraction. So, by Theorem $1, T$ has a fixed point.

Now, suppose that $u$ and $v$ are two fixed point of $T$. If $u \neq v$, then $d(T u, T v)>0$. Also $\alpha(u, v) \geq 1$, because $u, v \in \operatorname{Fix}(T)$, hence (8) implies that

$$
\begin{aligned}
\tau+F(d(u, v)) & =\tau+F(d(T u, T v)) \leq \tau+\alpha(u, v) F(d(T u, T v)) \\
& \leq F\left(m(u, v)+L N_{2}(u, v)\right) \leq F(m(u, v)+L d(u, T u)) \\
& =F(m(u, v)+0)=F(m(u, v))
\end{aligned}
$$

where

$$
\begin{aligned}
m(u, v) & =\max \left\{d(u, v), d(u, T u), d(v, T v), \frac{d(u, T v)+d(v, T u)}{2}\right\} \\
& =\max \left\{d(u, v), 0,0, \frac{d(u, v)+d(v, u)}{2}\right\}=d(u, v) .
\end{aligned}
$$

So, we have

$$
\tau+F(d(u, v)) \leq F(d(u, v)),
$$

which is contradicted by positivity of $\tau$. So, $u=v$. 
Corollary 1 ([3], Theorem 3.1). Let $(X, d)$ be a complete metric space and $T: X \rightarrow X$ be an $\alpha$-type almost- $F$-contraction, where $F \in \mathcal{F}$, satisfying the following conditions:

(i) $T$ is $\alpha$-admissible,

(ii) there exists $x_{0} \in X$ such that $\alpha\left(x_{0}, T x_{0}\right) \geq 1$,

(iii) if $\left\{x_{n}\right\}$ is a sequence in $X$ such that $x_{n} \rightarrow x$ as $n \rightarrow \infty$ and $\alpha\left(x_{n}, x_{n+1}\right) \geq 1$ for all $n \in \mathbb{N}$, then $\alpha\left(x_{n}, x\right) \geq 1$, for all $n \in \mathbb{N}$.

Then, $T$ has a fixed point.

Proof. It is enough to notice that $T$ is an almost- $\alpha F$-weak contraction in which $m(x, y)=$ $d(x, y)$. One can prove this corollary by applying the proof of Theorem 1 , without needing to continuity of $T$ or $F$.

The following corollaries are some obvious results of Theorem 1.

Corollary 2. Let $(X, d)$ be a complete metric space and $T: X \rightarrow X$ be an almost F-contraction. Then, $T$ has a fixed point.

Proof. In Theorem 1, put $\alpha(x, y)=1$, for each $x, y \in X$.

Corollary 3. Let $(X, d)$ be a complete metric space and $T: X \rightarrow X$ be an F-contraction. Then, $T$ has a unique fixed point.

Proof. In the Theorem 1, put $\alpha(x, y)=1$, for each $x, y \in X$, and $L=0$.

The following example shows that Theorem 1 is a generalization of the Theorem 3.1 in [3].

Example 4. In the Example 3, we observed that the mapping $T$ is not an $\alpha$-type almost-Fcontraction. So, $T$ does not satisfy to Theorem 3.1 in [3]. But $T$ is an almost- $\alpha$ F-weak contraction, and we can easily see that $T$ satisfies all conditions of Theorem 1 and $(0,0)$ is a fixed point of $T$. Also, all conditions of the Theorem 2 are satisfied and $(0,0)$ is the unique fixed point of the map $T$.

Here, to obtain our next results, we first introduce the following definition.

Definition 12. Let $(X, d)$ be a metric space and $\alpha: X \times X \rightarrow(0,+\infty) \cup\{-\infty\}$ be a symmetric function. The mapping $T: X \rightarrow X$ is said to be an $\alpha$-type F-weak Suzuki contraction (for simplicity we write $\alpha$ F-weak Suzuki contraction) if there exists $F \in \mathcal{G}$ and $\tau>0$ such that for all $x, y \in X$ with $T x \neq T y$,

$$
\frac{1}{2} d(x, T x) \leq d(x, y) \quad \text { implies that } \tau+\alpha(x, y) F(d(T x, T y)) \leq F(m(x, y))
$$

where $m(x, y)$ is defined as in Definition 11 .

Example 5. Let $X=\{0,1,2\}$ be endowed with the metric $d$ defined by

$$
d(x, y)=|x-y|
$$


And $T: X \rightarrow X$ is defined as follows

$$
T(1)=T(2)=1 \quad \text { and } \quad T(0)=2 .
$$

Furthermore, suppose that $\alpha(x, y)=1$, for all $x, y \in X$. It is easily verified that, for each $F \in \mathcal{F}$, the mapping $T$ is not an $\alpha$-type $F$-Suzuki contraction. Indeed, for any $\tau>0$ and $F \in \mathcal{F}$, we have

$$
\frac{1}{2} d(0, T 0)=\frac{1}{2} d(0,2)=1=d(0,1),
$$

and

$$
\tau+\alpha(0,1) F(d(T 0, T 1))=\tau+F(d(2,1))=\tau+F(1) .
$$

On the other hand, we have

$$
F(d(0,1))=F(1)
$$

And $\tau+F(1)>F(1)$. So, $T$ is not an $\alpha$-type $F$-Suzuki contraction. But one can easily see that, for $0<\tau \leq \ln 2$ and $F(t)=\ln t$, if $d(T x, T y) \neq 0$ then

$$
\frac{1}{2} d(x, T x) \leq d(x, y) \quad \text { implies that } \tau+\alpha(x, y) F(d(T x, T y)) \leq F(m(x, y))
$$

where $m(x, y)$ is defined as in Definition 11. For example, $d(T(0), T(1))=d(2,1)=1$ and

$$
m(0,1)=\max \left\{d(0,1), d(0, T 0), d(1, T 1), \frac{d(0, T 1)+d(1, T 0)}{2}\right\}=2,
$$

and we have

$$
\tau+\alpha(0,1) F(d(T 0, T 1))=\tau+F(1) \leq \ln 2+\ln 1=\ln 2 .
$$

On the other hand, we have

$$
F(m(0,1))=F(2)=\ln 2 .
$$

Hence,

$$
\tau+\alpha(0,1) F(d(T 0, T 1)) \leq F(m(0,1)) .
$$

In the same manner, we can easily check that (9) is satisfied for $x=0, y=2$. Therefore, (9) is satisfied for any $x, y \in X$ which $d(T x, T y) \neq 0$. So, $T$ is an $\alpha$ F-weak Suzuki contraction.

Theorem 3. Let $(X, d)$ be a complete metric space and $T: X \rightarrow X$ be an $\alpha$ F-weak Suzuki contraction, satisfying the following conditions:

(i) $T$ is $\alpha$-admissible,

(ii) there exists $x_{0} \in X$ such that $\alpha\left(x_{0}, T x_{0}\right) \geq 1$,

(iii) if $\left\{x_{n}\right\}$ is a sequence in $X$ such that $x_{n} \rightarrow x$ as $n \rightarrow \infty$ and $\alpha\left(x_{n}, x_{n+1}\right) \geq 1$, for all $n \in \mathbb{N} \cup\{0\}$, then $\alpha\left(x_{n}, x\right) \geq 1$, for all $n \in \mathbb{N} \cup\{0\}$,

(iv) T has the K-property.

Then, $T$ has a fixed point in $X$. 
Proof. Let $x_{0} \in X$ be such that $\alpha\left(x_{0}, T x_{0}\right) \geq 1$. For any $n \in \mathbb{N} \cup\{0\}$, define:

$$
x_{n+1}=T\left(x_{n}\right) \text {. }
$$

Since $T$ is $\alpha$-admissible, one can easily obtain that

$$
\alpha\left(x_{n}, x_{n+1}\right) \geq 1, \quad \forall n \in \mathbb{N} \cup\{0\} .
$$

If $x_{n_{0}+1}=x_{n_{0}}$ for some $n_{0} \in \mathbb{N} \cup\{0\}$, then $x_{n_{0}}$ is a fixed point of $T$. So, we can assume that $x_{n+1} \neq x_{n}$ for each $n \in \mathbb{N} \cup\{0\}$, i.e. $d\left(x_{n}, x_{n+1}\right)>0$ and so

$$
\frac{1}{2} d\left(x_{n}, T x_{n}\right)=\frac{1}{2} d\left(x_{n}, x_{n+1}\right)<d\left(x_{n}, x_{n+1}\right) .
$$

Now, since $T$ is an $\alpha F$-weak Suzuki contraction, there exist $F \in \mathcal{G}$ and $\tau>0$ such that if $d(T x, T y)>0$, then

$$
\frac{1}{2} d(x, T x) \leq d(x, y) \quad \text { implies that } \quad \tau+\alpha(x, y) F(d(T x, T y)) \leq F(m(x, y)),
$$

where $m(x, y)$ is defined as in Definition 11.

Therefore, by (11) and (12)

$$
\begin{aligned}
\tau+F\left(d\left(T x_{n}, T x_{n+1}\right)\right) & \leq \tau+\alpha\left(x_{n}, x_{n+1}\right) F\left(d\left(T x_{n}, T x_{n+1}\right)\right) \\
& \leq F\left(m\left(x_{n}, x_{n+1}\right)\right),
\end{aligned}
$$

in which

$$
\begin{aligned}
m\left(x_{n}, x_{n+1}\right) & =\max \left\{d\left(x_{n}, x_{n+1}\right), d\left(x_{n}, T x_{n}\right), d\left(x_{n+1}, T x_{n+1}\right), \frac{d\left(x_{n}, T x_{n+1}\right)+d\left(x_{n+1}, T x_{n}\right)}{2}\right\} \\
& =\max \left\{d\left(x_{n}, x_{n+1}\right), d\left(x_{n+1}, x_{n+2}\right), \frac{d\left(x_{n}, x_{n+2}\right)}{2}\right\} \\
& \leq \max \left\{d\left(x_{n}, x_{n+1}\right), d\left(x_{n+1}, x_{n+2}\right), \frac{d\left(x_{n}, x_{n+1}\right)+d\left(x_{n+1}, x_{n+2}\right)}{2}\right\} \\
& \leq \max \left\{d\left(x_{n}, x_{n+1}\right), d\left(x_{n+1}, x_{n+2}\right)\right\} .
\end{aligned}
$$

Now, if $d\left(x_{n_{0}+1}, x_{n_{0}+2}\right) \geq d\left(x_{n_{0}}, x_{n_{0}+1}\right)$ for some $n_{0} \in \mathbb{N} \cup\{0\}$, then

$$
m\left(x_{n_{0}}, x_{n_{0}+1}\right) \leq d\left(x_{n_{0}+1}, x_{n_{0}+2}\right),
$$

and since $F$ is strictly increasing,

$$
F\left(m\left(x_{n_{0}}, x_{n_{0}+1}\right)\right) \leq F\left(d\left(x_{n_{0}+1}, x_{n_{0}+2}\right)\right) .
$$

Therefore by (13)

$$
\tau+F\left(d\left(x_{n_{0}+1}, x_{n_{0}+2}\right)\right) \leq F\left(d\left(x_{n_{0}+1}, x_{n_{0}+2}\right)\right) .
$$

So, $\tau \leq 0$ a contradiction. Consequently,

$$
d\left(x_{n+1}, x_{n+2}\right)<d\left(x_{n}, x_{n+1}\right), \forall n \in \mathbb{N} .
$$


Therefore,

$$
m\left(x_{n}, x_{n+1}\right) \leq d\left(x_{n}, x_{n+1}\right), \forall n \in \mathbb{N} \cup\{0\} .
$$

So, from (13) and (14) one can obtain that

$$
\tau+F\left(d\left(x_{n+1}, x_{n+2}\right)\right) \leq F\left(d\left(x_{n}, x_{n+1}\right)\right),
$$

or

$$
F\left(d\left(x_{n+1}, x_{n+2}\right)\right) \leq F\left(d\left(x_{n}, x_{n+1}\right)\right)-\tau \text {. }
$$

In general, one can get

$$
F\left(d\left(x_{n+1}, x_{n+2}\right)\right) \leq F\left(d\left(x_{0}, x_{1}\right)\right)-n \tau .
$$

Hence,

$$
\lim _{n \rightarrow \infty} F\left(d\left(x_{n}, x_{n+1}\right)\right)=-\infty,
$$

which together with (G2) and Lemma 1, gives

$$
\lim _{n \rightarrow \infty} d\left(x_{n}, x_{n+1}\right)=0 .
$$

Now, we claim that $\left\{x_{n}\right\}$ is a Cauchy sequence. If it is not true, then by Lemma 2, there exists $\varepsilon_{0}>0$ and two sequences of positive integers $\left\{n_{k}\right\}$ and $\left\{m_{k}\right\}$ with $n_{k}>m_{k}>k$ such that $d\left(x_{m_{k}}, x_{n_{k}}\right)>\varepsilon_{0}, d\left(x_{m_{k}}, x_{n_{k}-1}\right)<\varepsilon_{0}$ and

(L1) $\lim _{k \rightarrow \infty} d\left(x_{n_{k}}, x_{m_{k}}\right)=\varepsilon_{0}$,

(L2) $\lim _{k \rightarrow \infty} d\left(x_{n_{k}}, x_{m_{k}-1}\right)=\varepsilon_{0}$,

(L3) $\lim _{k \rightarrow \infty} d\left(x_{n_{k}+1}, x_{m_{k}}\right)=\varepsilon_{0}$,

(L4) $\lim _{k \rightarrow \infty} d\left(x_{n_{k}+1}, x_{m_{k}-1}\right)=\varepsilon_{0}$.

Therefore, with notice to definition of $m(x, y)$ we have:

$$
\begin{aligned}
\lim _{k \rightarrow \infty} m\left(x_{n_{k}}, x_{m_{k}-1}\right)= & \lim _{k \rightarrow \infty} \max \left\{d\left(x_{n_{k}}, x_{m_{k}-1}\right), d\left(x_{n_{k}}, x_{n_{k}+1}\right), d\left(x_{m_{k}-1}, x_{m_{k}}\right),\right. \\
& \left.\frac{d\left(x_{n_{k}}, x_{m_{k}}+d\left(x_{m_{k}-1}, x_{n_{k}}+1\right)\right)}{2}\right\}=\max \left\{\varepsilon_{0}, 0,0, \frac{\varepsilon_{0}+\varepsilon_{0}}{2}\right\}=\varepsilon_{0} .
\end{aligned}
$$

So

$$
\lim _{k \rightarrow \infty} m\left(x_{n_{k}}, x_{m_{k}-1}\right)=\varepsilon_{0}
$$

On the other hand, since $\lim _{k \rightarrow \infty} d\left(x_{n_{k}}, x_{m_{k}-1}\right)=\varepsilon_{0}>0$, and $\lim _{k \rightarrow \infty} d\left(x_{n_{k}}, x_{n_{k}+1}\right)=0$, by considering a subsequence if necessary, one can assume that, there exists $k_{1} \in \mathbb{N}$ such that for any $k>k_{1}$ and $n_{k}>m_{k}>k$

$$
d\left(x_{n_{k}}, x_{n_{k}+1}\right) \leq d\left(x_{n_{k}}, x_{m_{k}-1}\right)
$$

So, it is clear that

$$
\frac{1}{2} d\left(x_{n_{k}}, T x_{n_{k}}\right)=\frac{1}{2} d\left(x_{n_{k}}, x_{n_{k}+1}\right)<d\left(x_{n_{k}}, x_{m_{k}-1}\right), \quad \forall k>k_{1} \text { and } n_{k}>m_{k}>k .
$$


Also, using the K-property, there exists $k_{2} \in \mathbb{N}$ such that

$$
\alpha\left(x_{n_{k}}, x_{m_{k}-1}\right) \geq 1, \quad \forall k>k_{2} .
$$

Let $k \geq \max \left\{k_{1}, k_{2}\right\}$, then from (18), (17) and (12) we have

$$
\begin{aligned}
\tau+F\left(d\left(T x_{n_{k}}, x_{m_{k}-1}\right)\right) & \leq \tau+\alpha\left(x_{n_{k}}, x_{m_{k}-1}\right) F\left(d\left(T x_{n_{k}}, T x_{m_{k}-1}\right)\right) \\
& \leq F\left(m\left(x_{n_{k}}, x_{m_{k}-1}\right)\right) .
\end{aligned}
$$

Letting $n \rightarrow \infty$, since $F$ is continuous, by (L1) and (16) we have

$$
\tau+F\left(\varepsilon_{0}\right) \leq F\left(\varepsilon_{0}\right)
$$

which is a contradiction, as $\tau>0$. Consequently, $\left\{x_{n}\right\}$ is a Cauchy sequence in the complete metric space $X$. So, there exists $u \in X$ such that $x_{n} \rightarrow u$, as $n \rightarrow \infty$. To complete the proof, we show that $u$ is a fixed point of $T$. At first, we claim that, for all $n \geq 0$

$$
\frac{1}{2} d\left(x_{n}, x_{n+1}\right) \leq d\left(x_{n}, u\right) \quad \text { or } \quad \frac{1}{2} d\left(x_{n+1}, x_{n+2}\right) \leq d\left(x_{n+1}, u\right) .
$$

In fact, if for some $n_{0} \geq 0$, both of them are false then we will have

$$
\frac{1}{2} d\left(x_{n_{0}}, x_{n_{0}+1}\right)>d\left(x_{n_{0}}, u\right) \text { and } \frac{1}{2} d\left(x_{n_{0}+1}, x_{n_{0}+2}\right)>d\left(x_{n_{0}+1}, u\right) .
$$

So, with notice of (14) we have

$$
\begin{aligned}
d\left(x_{n_{0}}, x_{n_{0}+1}\right) & \leq d\left(x_{n_{0}}, u\right)+d\left(u, x_{n_{0}+1}\right)<\frac{1}{2} d\left(x_{n_{0}}, x_{n_{0}+1}\right)+\frac{1}{2} d\left(x_{n_{0}+1}, x_{n_{0}+2}\right) \\
& \leq \frac{1}{2} d\left(x_{n_{0}}, x_{n_{0}+1}\right)+\frac{1}{2} d\left(x_{n_{0}}, x_{n_{0}+1}\right)=d\left(x_{n_{0}}, x_{n_{0}+1}\right) .
\end{aligned}
$$

Which is a contradiction and the claim is proved.

Well, let us begin with the first part of (19), i.e. suppose that

$$
\frac{1}{2} d\left(x_{n}, x_{n+1}\right) \leq d\left(x_{n}, u\right)
$$

and in contrary, assume that $T u \neq u$. Without lose of generality, one can assume that $T x_{n} \neq T u$, for all $n \in \mathbb{N}$. (Indeed, if $x_{n+1}=T x_{n}=T u$ for infinite values of $n$, then uniqueness of the limit concludes that $T u=u$ ). Then, from (14) and (iii) we get

$$
\begin{aligned}
\tau+F\left(d\left(x_{n+1}, T u\right)\right) & =\tau+F\left(d\left(T x_{n}, T u\right)\right) \\
& \leq \tau+\alpha\left(x_{n}, u\right) F\left(d\left(T x_{n}, T u\right)\right) \leq F\left(m\left(x_{n}, u\right)\right)
\end{aligned}
$$

and since $F$ is continuous on $(0,+\infty)$ and $d(u, T u)>0$ as $n \rightarrow \infty$, we get

$$
\tau+F(d(u, T u)) \leq F\left(\lim _{n \rightarrow \infty} m\left(x_{n}, u\right)\right) .
$$

But

$$
m\left(x_{n}, u\right)=\max \left\{d\left(x_{n}, u\right), d\left(x_{n}, x_{n+1}\right), d(u, T u), \frac{d\left(x_{n}, T u\right)+d\left(u, x_{n+1}\right)}{2}\right\} .
$$

So, we have

$$
\lim _{n \rightarrow \infty} m\left(x_{n}, u\right)=\max \left\{0,0, d(u, T u), \frac{d(u, T u)+0}{2}\right\}=d(u, T u) .
$$


Therefore, if $d(u, T u) \neq 0$ then from (20) we have

$$
\tau+F(d(u, T u)) \leq F(d(u, T u))
$$

which is contradicted by positivity of $\tau$. So, $d(u, T u)=0$, i.e. $T u=u$. Finally, if we assume that the second part of (19) is true, i.e.

$$
\frac{1}{2} d\left(x_{n+1}, x_{n+2}\right) \leq d\left(x_{n+1}, u\right)
$$

Then, as the same manner, we can prove that $d(u, T u)=0$, i.e. $T u=u$.

The next result establishes a sufficient condition for uniqueness of fixed point of an $\alpha F$ weak Suzuki contraction.

Theorem 4. Suppose that all the conditions of Theorem 3 are satisfied. In addition, assume that $\alpha(x, y) \geq 1$, for all $x, y \in$ Fix $(T)$. Then, $T$ has a unique fixed point.

Proof. Suppose that $u$ and $v$ are two fixed point of $T$. If $u \neq v$, then $d(T u, T v)>0$. Also $\alpha(u, v) \geq 1$, because $u, v \in \operatorname{Fix}(T)$. Also, it is clear that $\frac{1}{2} d(u, T u)=0<d(u, v)$. Hence, (12) implies that

$$
\tau+F(d(u, v))=\tau+F(d(T u, T v)) \leq \tau+\alpha(u, v) F(d(T u, T v)) \leq F(m(u, v)),
$$

where

$$
\begin{aligned}
m(u, v) & =\max \left\{d(u, v), d(u, T u), d(v, T v), \frac{d(u, T v)+d(v, T u)}{2}\right\} \\
& =\max \left\{d(u, v), 0,0, \frac{d(u, v)+d(v, u)}{2}\right\}=d(u, v) .
\end{aligned}
$$

So, we have

$$
\tau+F(d(u, v)) \leq F(d(u, v)),
$$

which is a contradiction, as $\tau>0$. So, $u=v$.

Since each $\alpha$-type F-Suzuki contraction is obviously an $\alpha$ F-weak Suzuki contraction, the following two corollaries are elementary results of Theorems 3 and 4 respectively.

Corollary 4 ([3], Theorem 3.3). Let $(X, d)$ be a complete metric space and $T: X \rightarrow X$ be an $\alpha$ type F-Suzuki contraction, satisfying the conditions (i)-(iv) of Theorem 3. Then, $T$ has a fixed point.

Corollary 5 ([3], Theorem 3.4). If in the Corollary 4, we further assume that $\alpha(x, y) \geq 1$, for all $x, y \in \operatorname{Fix}(T)$, then $T$ has a unique fixed point.

The following example shows that Theorem 3 is a generalization of Theorem 3.3 in [3].

Example 6. In the Example 5, we saw that the mapping $T$ is not an $\alpha$-type F-Suzuki contraction. So, $T$ does not satisfy to Theorem 3.3 in [3]. But $T$ is an $\alpha$ F-weak Suzuki contraction, and we can easily see that $T$ satisfies all conditions of Theorem 3. And $u=1$ is a fixed point of T. Also, all conditions of Theorem 4 are satisfied and $u=1$ is the unique fixed point of $T$. 


\section{CONSEQUENCES}

In this section, one of the consequences of our research in metric spaces with graph is introduced. First, we remind a series of definitions and notions in graph theory.

Let $(X, d)$ be a metric space and $\Delta=\{(x, x), x \in X\}$. Suppose that $G$ is a graph, $V(G)$ is the set of all its vertices and $E(G)$ is the set of all edges of $G$. We say that $G$ has no parallel edge, if $(x, y),(y, x) \in E(G)$ implies that $x=y$. Also $G$ is directed if the edges have a direction associated with them. We denoted by $\mathcal{G}(X)$ the set of all directed graph $G$ with no parallel edge in which $V(G)=X$ and $\Delta \subseteq E(G)$.

Definition 13 ([9]). The mapping $T: X \rightarrow X$ is called G-continuous, if for each sequence $\left\{x_{n}\right\}_{n=1}^{\infty}$ in $X$ that $\left(x_{n}, x_{n+1}\right) \in E(G) \forall n \in \mathbb{N}$ and $x_{n} \rightarrow x$ as $n \rightarrow \infty$ one can conclude that $T x_{n} \rightarrow T x$ as $n \rightarrow \infty$.

Theorem 5. Let $(X, d)$ be a complete metric space endowed with a graph $G \in \mathcal{G}(X)$ and $T: X \rightarrow X$ be a mapping with the following conditions:

(i) for all $x, y \in X,(x, y) \in E(G) \Rightarrow(T x, T y) \in E(G)$,

(ii) there exists $x_{0} \in X$ such that $\left(x_{0}, T x_{0}\right) \in E(G)$,

(iii) for any sequence $\left\{x_{n}\right\}_{n=1}^{\infty} \subseteq X$ and $x \in X$ if $\lim _{n \rightarrow \infty} x_{n}=x$ and $\left(x_{n}, x_{n+1}\right) \in E(G)$, for all $n \in \mathbb{N}$, then $\left(x_{n}, x\right) \in E(G)$, for all $n \in \mathbb{N}$,

(iv) there exist $F \in \mathcal{F}$, and $\tau>0$ and $L \geq 0$ such that if $(x, y) \in E(G)$ and $d(T x, T y)>0$ then

$$
\tau+F(d(T x, T y)) \leq F\left(m(x, y)+L N_{1}(x, y)\right),
$$

where $m(x, y)$ and $N_{1}(x, y)$ are defined as in Definition 11.

Then, if $T$ is $G$-continuous or $F$ is continuous, then $T$ has a fixed point.

Proof. Define $\alpha: X \times X \rightarrow(0,+\infty) \cup\{-\infty\}$ by

$$
\alpha(x, y)= \begin{cases}1, & \text { if }(x, y) \in E(G), \\ -\infty, & \text { otherwise. }\end{cases}
$$

We show that all condition of Theorem 1 are satisfied. First, prove that $T$ is $\alpha$-admissible, it is enough to notice that if $\alpha(x, y) \geq 1$, then $(x, y) \in E(G)$ and it follows from $(i)$ that $(T x, T y) \in$ $E(G)$. Hence, $\alpha(T x, T y) \geq 1$. By $(i i)$ there exists $x_{0} \in X$ such that $\left(x_{0}, T x_{0}\right) \in E(G)$ i.e. $\alpha\left(x_{0}, T x_{0}\right) \geq 1$. Now, suppose that $\left\{x_{n}\right\}_{n=1}^{\infty} \subseteq X$ is a sequence in $X$ such that $x_{n} \rightarrow x$ as $n \rightarrow \infty$ and $\alpha\left(x_{n}, x_{n+1}\right) \geq 1$, for all $n \in \mathbb{N}$, Then, $\left(x_{n}, x_{n+1}\right) \in E(G)$ and it follows from (iv) that $\left(x_{n}, x\right) \in E(G)$, for all $n \in \mathbb{N}$, i.e. $\alpha\left(x_{n}, x\right) \geq 1$, for all $n \in \mathbb{N} \cup\{0\}$. Finally, we show that $T$ is an almost- $\alpha F$-weak contraction on $X$. For this, suppose that $x, y \in X$ and $d(T x, T y)>0$. If $(x, y) \notin E(G)$, then $\alpha(x, y)=-\infty$ and so we have

$$
\tau+\alpha(x, y) F(d(T x, T y)) \leq F\left(m(x, y)+L N_{1}(x, y)\right) .
$$

If $(x, y) \in E(G)$, then $\alpha(x, y)=1$ and it follows from (21) that

$$
\tau+\alpha(x, y) F(d(T x, T y))=\tau+F(d(T x, T y)) \leq F\left(m(x, y)+L N_{1}(x, y)\right) .
$$

Thus, $T$ is an almost- $\alpha F$-weak contraction on $X$. It follow from all the conditions of Theorem 1 are satisfied and $\mathrm{T}$ has a fixed point in $X$. 
The following result is immediately deduced from Theorem 5.

Corollary 6 ([6], Theorem 4.1). Let $(X, d)$ be a complete metric space endowed with a graph $G \in \mathcal{G}(X)$ and $T: X \rightarrow X$ be a mapping with the following conditions:

(i) for all $x, y \in X,(x, y) \in E(G) \Rightarrow(T x, T y) \in E(G)$,

(ii) there exists $x_{0} \in X$ such that $\left(x_{0}, T x_{0}\right) \in E(G)$,

(iii) for any sequence $\left\{x_{n}\right\}_{n=1}^{\infty} \subseteq X$ and $x \in X$ if $\lim _{n \rightarrow \infty} x_{n}=x$ and $\left(x_{n}, x_{n+1}\right) \in E(G)$, for all $n \in \mathbb{N}$, then $\left(x_{n}, x\right) \in E(G)$, for all $n \in \mathbb{N}$ or $T$ is $G$-continuous.

(iv) there exist $F \in \mathcal{F}, \tau>0$ and $L \geq 0$ such that if $(x, y) \in E(G)$ and $d(T x, T y)>0$ then

$$
\tau+F(d(T x, T y)) \leq F\left(d(x, y)+L N_{1}(x, y)\right) .
$$

Then, $T$ has a fixed point.

Acknowledgment. The authors would like to thank anonymous referees for valuable comments and careful reading.

\section{REFERENCES}

[1] Batra R., Vashistha S. Fixed points of an F-contraction on metric spaces with a graph. Int. J. Comput. Math. 2014, 91, 1-8.

[2] Banach S. Sur les opérations dans les ensembles abstraits et leurs applications aux équations intégrales. Fund. Math. 1922, 3, 133-181.

[3] Budhia L.B, Kumam P., Martinez-Moreno J., Gopal D. Extensions of almost-F and F-Suzuki contractions with graph and some applications to fractional calculus. Fixed Point Theory Appl. 2016. Article number 2 (2016). doi:10.1186/s13663-015-0480-5

[4] Choudhury B.S, Konar P., Rhoades B.E, Metiya N. Fixed point theorems for generalized weakl contractive mappings. Nonlinear Anal. 2011, 74 (6), 2116-2126.

[5] Ćirić L.B. A generalization of Banachs contraction principle. Proc. Amer. Math. Soc. 1974, 45 (2), 267-273.

[6] Cosentino M., Vetroa P. Fixed point results for F-contractive mappings of Hardy-Rogers-type. Filomat 2014, 28 (4), 715-722. doi:10.2298/FIL1404715C

[7] Gopal D., Abbas M., Patel D.K., Vetro C. Fixed points of $\alpha$-type F-contractive mappings with an application to nonlinear fractional differential equation. Acta Math. Sci. 2016, 36 (3), 957-970.

[8] Gopal D., Abbas M., Vetro C., Patel D.K. Some coincidence and periodic points results in a metric space endowed with a graph and applications. Banach J. Math. Anal. 2015, 9 (3), 128-139. doi:10.15352/bjma/09-3-9

[9] Jachymski J. The contraction principle for mapping on a metric space with a graph. Proc. Am. Math. Soc. 2008, 136, 1359-1373.

[10] Karapinar E., Kutbi M.A., Piri H., ÓRegan D. Fixed points of conditionally F-contractions incomplete metric-like spaces. Fixed Point Theory Appl. 2015. Article number 126 (2015). doi:10.1186/s13663-015-0377-3

[11] Karapinar E., Samet B. Generalized $\alpha-\psi$ contractive type mappings and related fixed point theorems with applications. Abstr. Appl. Anal. 2012, 2012. Article ID 793486. doi:10.1155/2012/793486

[12] Kirk W., Sims B. Handbook of metric fixed point theory. Springer, 2001.

[13] Meir A., Keeler E. A theorem on contraction mappings. J. Math. Anal. Appl. 1969, 28, 326-329. 
[14] Minak G., Helvaci A., Altun I. Ćirić-type generalized F-contractions on complete metric spaces and fixed point results. Filomat 2014, 28 (6), 1143-1151.

[15] Mohammadi B., Rezapour S., Shahzad N. Some results on fixed points of $\alpha-\psi$-Ciric generalized multifunctions. Fixed Point Theory Appl. 2013. Article number 24 (2013). doi:10.1186/1687-1812-2013-24

[16] Piri H., Kumam P. Some fixed point theorems concerning F-contraction in complete metric spaces. Fixed Point Theory Appl. 2014. Article number 210 (2014). doi:10.1186/1687-1812-2014-210

[17] Rhoades B.E. Some theorems on weakly contractive maps. Nonlinear Anal. 2001, 47, 2683-2693.

[18] Salimi P., Latif A., Hussain N. Modified $\alpha-\psi$-contractive mappings with applications. Fixed Point Theory Appl. 2013. Article number 151 (2013). doi:10.1186/1687-1812-2013-151

[19] Samet B., Vetro C., Vetro P. Fixed point theorems for $\alpha$ - $\psi$-contractive type mappings. Nonlinear Anal. 2012, 75, 2154-2165.

[20] Secelean N.A. Iterated function systems consisting of F-contractions. Fixed Point Theory Appl. 2013. Article number 277 (2013). doi:10.1186/1687-1812-2013-277

[21] Sgroi M., Vetro C. Multi-valued F-contractions and the solution of certain functional and integral equations. Filomat 2013, 27, $1259-1268$.

[22] Singh S.L, Kamal R., De la Sen M., Chugh R. A fixed point theorem for generalized weak contractions. Filomat 2015, 29 (7), 1481-1490.

[23] Suzuki T. A new type of fixed point theorem in metric spaces. Nonlinear Anal. 2009, 71 (11), 5313-5317.

[24] Wardowski D. Fixed points of a new type of contractive mappings in complete metric spaces. Fixed Point Theory Appl. 2012. Article number 94 (2012). doi:10.1186/1687-1812-2012-94

[25] Wardowski D., Van Dung N. Fixed points of F-weak contractions on complete metric spaces. Demonstr. Math. 2014, 47 (1), 146-155.

Received 20.01.2019

Тахері А., Фараджаде А.П. Нова характеризачія майже-F-стиску $\alpha$-типу i F-Сузукі стиску $\alpha$ типу в метричних просторах і теореми про фіксовану точку для них // Карпатські матем. публ. — 2019. — T.11, №2. — С. 475-492.

У цій статті запропоновано нове узагальнення майже- $F$-стиску $\alpha$-типу і продовження $F$ Сузукі стиску $\alpha$-типу. Крім того, доведено деякі нові теореми про фіксовану точку для цих випадків. Наведено приклади і застосування, які ілюструють основні результати. Результати цієї статті покращують результати, які добре відомі у літературі.

Ключові слова і фрази: майже-F-стиск $\alpha$-типу, F-Сузукі стиск $\alpha$-типу. 